\title{
Smooth Nodule
}

National Cancer Institute

\section{Source}

National Cancer Institute. Smooth Nodule. NCI Thesaurus. Code C157666.

Featureless marg in that cleanly demarcates the nodule from surrounding lung with no undulations or irregularities. 